\title{
Real Time Lake Water Level Evaporation and Variablity Monitoring System using Internet of Things
}

\author{
S.Magesh Kumar, V.Parthipan, S.Rinesh
}

\begin{abstract}
Water is one of the nature's profitable endowments, which oversees life on earth. Human headways over the world have succeeded or kicked the bucket depending on the openness of this key, so to defeat this issue proposed work used savvy systems utilizing IoT. This venture incorporates different highlights like GSM based observing, dampness and temperature detecting, Water vanishing level. The worldwide framework for versatile correspondence (GSM) is utilized worldwide for constant recognition, overwhelming and alarming of dam water level. This propel innovation utilizes short message administrations (SMS) to straightforwardly administration and screen the opening and closing of the shade in dam. Through the SMS this system cautions the people remaining nearby places with respect to the expansion in water level. Temperature gadget, sense the progressions in atmosphere temperature and take up pertinent live like easing the overabundance water in dam for water system reason in seasons. This paper gives a nearby model of the framework that detects the progressions like temperature and water level refinement exploitation sensors, and flood recognition exploitation GSM technology. This venture is to encase the adjustments in temperature and dampness of water level in lake. because of a worldwide temperature alteration, the water vanishing in the lake is expanded, which may prompt lack in water. This undertaking will help individuals to quantify the level of water got dissipated. This venture will make individuals mindful about the mugginess happened because of dissipation of water.
\end{abstract}

Keywords - water, temperature, flood

\section{INTRODUCTION}

Water has been worshiped always supporting properties in each one of the hallowed writings. Vedas have unequivocally adulated water in all its reasonable properties. The total water resources on earth are assessed to be around 1360 Million cubic $\mathrm{km}$. Out of which just around (33.5 Million cubic $\mathrm{km}$ ) is new water. India has only $4 \%$ of total ordinary flood of the surges of the world regardless of the way that it oversees $16 \%$ of the aggregate people. The per capitation availability of water in the country is only 1820 $\mathrm{m} /$ year, stood out from $40855 \mathrm{~m} /$ year in Brazil, $8902 \mathrm{~m} /$ year in USA, $2215 \mathrm{~m} /$ year in China, $2808 \mathrm{~m} /$ year in Spain, 18162 m3/year in Australia, 3351 m3/year in France3614m/year in Mexico, and $3393 \mathrm{~m} / \mathrm{year}$ in Japan. The total water

Revised Manuscript Received on July 10, 2019.

Dr.S.Magesh Kumar, Assistant Professor, Department of Computer Science and Engineering, Saveetha School of Engineering, Saveetha University, Chennai, T.N, India. (E-mail: mmce6450@gmail.com)

Mr.V.Parthipan, Research Scholar, Department of Computer Science and Engineering, Saveetha School of Engineering, Saveetha University, Chennai, T.N, India. (E-mail: parthipansp@gmail.com)

Dr.S.Rinesh, Assistant Professor, Department of Computer Science and Engineering, Saveetha School of Engineering, Saveetha University, Chennai, T.N, India. (E-mail: rin.iimmba @ gmail.com) resources of India are assessed to be around 1,869 BCM. In

view of topographic, horological and diverse impediments, in a manner of speaking around $690 \mathrm{BCM}$ of total surface water is considered as utilizable. In the earlier days openness of water was disparaged. It is at present being comprehended that water, in spite of the way that renew capable, isn't an endless resource and can't be made or included as and when required, by any known mechanical means. The other basic confinement is that the openness of water during the time depends on the spatial and common assortment of precipitation. Likewise water may be inmodest a rainstorm season and uncommon in non-storm season, when for the most part required. The genius of man, thus, lies in his ability to alter the case of openness of water to suit needs. One of the commonest sorts of such modification is limit of water in the midst of rainstorm season for inescapable use in lean season. The standard methods are gigantic limit in like manner or phony positions. Recently innumerable have been created. Due to high temperatures and dry conditions in around $33 \%$ of the country, the vanishing mishaps have been seen to be extensive. Hence, it is fundamental to confine vanishing adversities in the stores/water bodies. The prerequisite for balancing activity of enormous vanishing setbacks expects more essential significance, in context of theobvious lack of water; the country will look in future. It has been assessed that the utilizable water resources the demand of 1123 , the need by 2025 Promotion to be met from surface water assets.

\section{ARCHITECTURE}

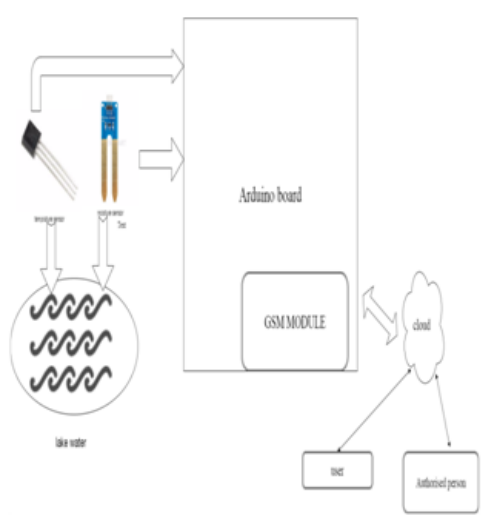

FIG 1: SYSTEM ARCHITETURE OF LAKE WATER SYSTEM 


\section{REAL TIME LAKE WATER LEVEL EVAPORATION AND VARIABLITY MONITORING SYSTEM USING INTERNET OF THINGS.}

\section{HARDWAREREQUIREMENTS}

The basic components of our project are Galileo Gen2, temperature sensor, breadboard, GSM, connecting wires.

\subsection{GALILEOGEN2}

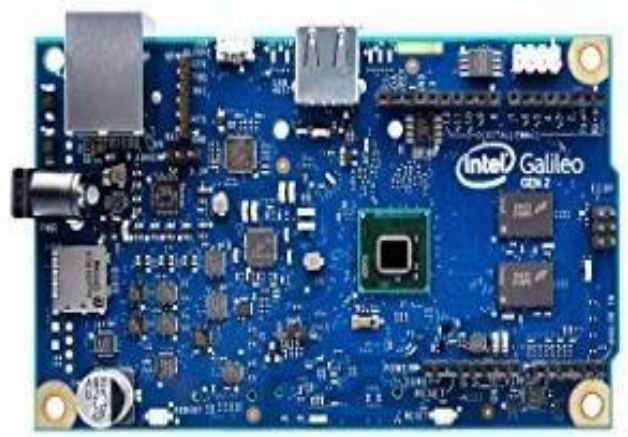

Fig 2: Intel Galileo Gen2

Intel Galileo has two versions of Galileo; they are referred as Gen1and Gen2. These boards are sometimes called "Breakout boards". Intel Galileo is the first in a line of Arduino-certified development boards on Intelx86 architecture and that is done for manufacturer and education groups. "Certified" means that the board is supported by the Arduino platform, but does not use an Arduino- supported processor. Although it is the lowest level in Arduino ecosystem, it also says thattheGalileo boards can be programmed using the Arduino IDE, it is compatible with Arduino peripherals such as shields.

3.2 GSM

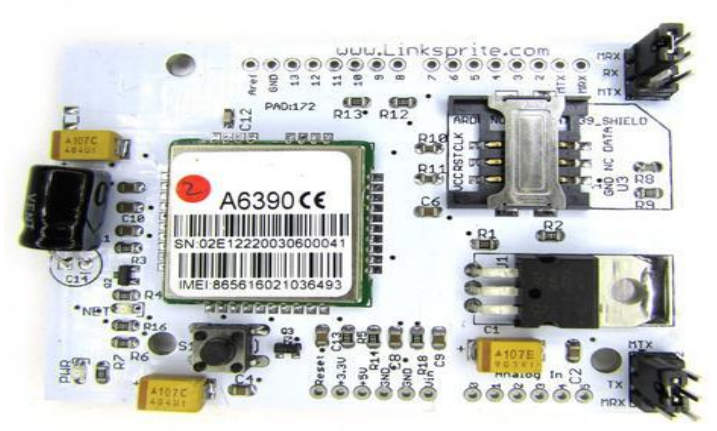

FIG 3: GSM MODULE BY LINKSPRITE

Global system for mobile communication (GSM)services is a standard application for mobilephones. These features are available to phone subscribers all over world. GSM helps to see our readings directlyin our mobile phone. Whenever we need can view our readings directly in phone with the help ofGSM.

\subsection{TEMPRATURE SENSOR}

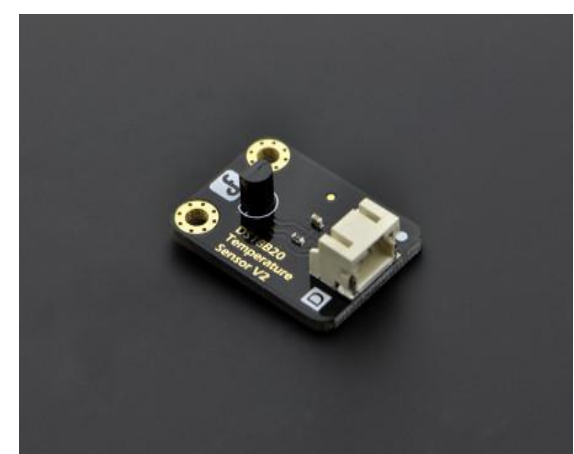

FIG 4: TEMPRATURE SENSOR

Temperature sensors are indispensable to an assortment of regular items. For instance, family unit stoves, coolers, and indoor regulators all depend on temperature upkeep and control keeping in mind the end goal to work legitimately. Temperature control additionally has applications in concoction designing. Cases of this incorporate keeping up the temperature of a substance reactor at the perfect setpoint, checking the temperature of a conceivable runaway response to guarantee the security of workers, and keeping up the temperature of streams discharged to the earth to limit destructive ecological effect.

\section{ALGORITHM}

- Step 1: Start theprocess

- Step 2 : initialize pin a 0 and ports

- Step 3 : Collect multiple sensordata

- Step 4 : get value from sensor anddisplay

- Step 5 : get the value anddata

- Step 6: store the data in plxdaq

- Step 7 : send sms

- Step 8 : repeat step 3 to step5

- Step 9 : end the process

\section{FLOW CHART}

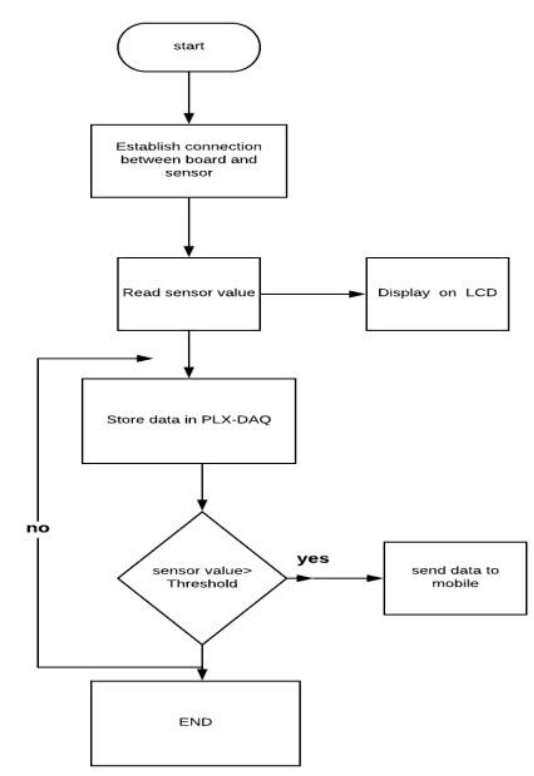

FIG 5: FLOW CHART 


\section{METHODOLOGY}

The framework can be utilized to quantify the level of water got dissipated and the moistness happened because of warmth. We are utilizing Arduino board, temperature sensors, moistness sensors to help for the estimation of water evaporation and testing process. The sensor has both the simple and the computerized yield.

Tools Used:

Ardunio board

GSM module

Temperature Sensor

\subsection{MODULES:}

- Actualize equipment set up

- Gather sensor information

- Information examination

- Casing work for IoT in cloud focus

- Execution examination

\section{Actualize equipment set up}

Equipment ought to be actualized by gathering the information's and the data that is required for the reason

\section{Gather sensor information}

Gather the sensors that are required for the water level monitoring and check its levels.

\section{Information examination}

Give the connections and check the reading and parameters that are displayed in it.

\section{Casing work for IOT in cloud focus}

Cloud gets the parameters and the readings and they are stored in the cloud centre

\section{Execution examination}

Collect all the data and all the connections are given to the board and all the outputs are performed in it.

\subsection{TOOLS ANDEXPLANATION}

The tools used in lake water monitoring system are Arduino software 1.85 version and it is connected with the GSM module, which surpasses the data from temperature sensor and stored it. The hardware and software components are connected and when connected to the Galileo Gen2 board need to follow some step by step procedure to get an accurate output need to check the device manager weather the ports are in "COM" and the board is connected to intel Galileo gen 2. later on launch the Arduino software and initialize the code for particular operation. Upload the code and save it and later select the serial monitor which shows you the output. Output provided by the serial monitor cannot be stored into device, to further go readings will be tickling. To store those data which cannot be stored by serial monitor we use "PLXDAQ" tool. With the help of this tool we can store our data and that data can be viewed anytime. the connections for GSM are given in interconnection way and the code for GSM would be merged with sensor code and it be provided with one contact number by which the data can be send to the user. the readings will be stored and a message will be sent from GSM. To check the data, it can be automatically checked in mobile phone. This is mainly done for making the task easier for human being, who are given task to check the water level manually and it can be a difficult for human to find the exact amount of reduction.

\section{RESULTS}

The sensor determine the water level evaporated from lake. The microcontroller controls all the functions and the output will be displayed. With the help of temperature sensor and the GalileoGen2, all the connections are given and the output is displayed. To save those data, plx-daqtool is used. Galileo microcontroller should get data in minutes. Galileo should analyze data and take correct action. Temperature sensor plays an important role in measuring the temperature and evaporation of water. The moisture level will be set asper the water level. . Galileo should upload the data and the values of the water level evaporation and temperature. The output will be displayed in COM with the help of the Arduino software as shown in fig. 5. The date, time and the temperature will be displayed init.

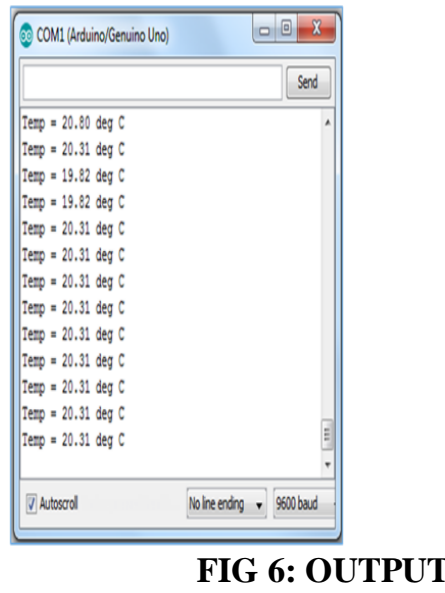

Efficient results are obtained from project. Table 1 shows the recorded data in lake area. The sensors that used are giving good results and the hardware implementation is successful and are getting the correct output. The sensors and board are working good thanexpected.

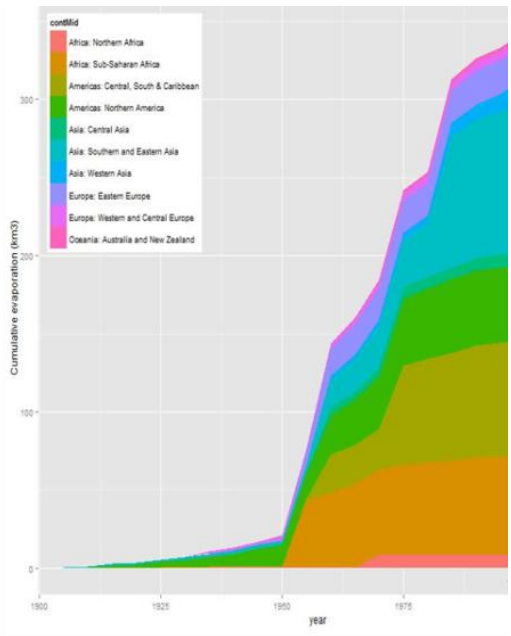

Fig 7 output 
TABLE 1 RECORDEDDATA

\begin{tabular}{|l|l|}
\hline $\begin{array}{l}\text { Date and Time } \\
(10.30 \text { a.m })\end{array}$ & $\begin{array}{l}\text { temperature } \\
(* \text { c) }\end{array}$ \\
\hline $24 / 04 / 2018$ & 34 \\
\hline $24 / 04 / 2018$ & 36 \\
\hline $25 / 04 / 2018$ & 32 \\
\hline $26 / 04 / 2018$ & 37 \\
\hline $27 / 04 / 2018$ & 32 \\
\hline
\end{tabular}

\section{APPLICATION AND FUTURESCOPE}

For future developments this lake water level monitoring system can be used for larger area. This system helps to check the water level of lake which gets evaporated by heat and changes based on season. The sensors are tested properly and the microcontroller is also working good. All observations are good and experimental testes prove that the human effort to measure evaporation ratio is good but using the sensor it can be useful in two ways by giving the accurate value of the water level evaporated. This helps us to improve the productivity and the water consumption. Further research could include the motor that is connected for on and off the microcontroller. But this system is the perfect solution to save the water. All project is mainly done for our welfare of human giving the best effort to measure the water level evaporation and happiness and mainly their work stress willreduce.

\section{CONCLUSION}

This project of lake water evaporation monitoring system can be used for larger area using larger number of sensor. This system is used to check the evaporation of water in particular temperature. The sensors and Galileo board are successfully interfaced and the wireless sensors are used at different nodes. This system mainly monitors the water evaporation level. If the temperature level is low then only the evaporation of the water will be less. This system checks and mainly monitors the behaviorof temperature of water and the people go to the lake end and measure the amount of water has been reduced due to the heat but they can't be more accuratewith the help of sensor it can automatically handheld the data. Hence all the sensors and microcontroller are giving good output. Hence the successful with output and this is mainly done for human welfare.

\section{REFERNCE:}

1. T.S.Yuvarani ,R.Archana "Water Level Monitor, Control and Alerting System Using GSM In Dams andIrrigation System based on Season" 2016

2. Pradeepkumar M, Monisha J , Pravenisha R, Praiselin V, Suganya Devi K"The Real Time Monitoring of Water QualityinIoT Environment"2016

3. Mr.KiranPatil, Mr.SachinPatil, Mr. Sanjay Patil, Mr.VikasPatil'Monitoring of Turbidity, PH \& Temperature ofWater Based on GSM"2015

4. John D. Lenters, John B. Anderton, Peter D. Blanken, "Assessing the Impacts of Climate Variability and Change on Great Lakes Evaporation"2015

5. A Gaddam, M Al-Hrooby, W F Esmael'Designing a Wireless Sensors Network forMonitoring and Predicting Droughts"2014
6. Rahul kumar, Surya S Durbha, Suryakant Ashok Sawant, J.Adinarayana.'IOT BASED ANDROID APPLICATION FOR CROP WATERREQUIREMENT"2014

7. Marvin E. Jensen"ESTIMATING EVAPORATION FROM WATER SURFACES"2010

8. W.E. Eichinger, J. Nichols, J.H. Prueger, L.E. Hipps, C.M.U. Neale, D.I. Cooper,AS. Bawazir"LAKE EVAPORATION ESTIMATION IN ARID ENVIRONMENTS"2003

9. J. J. Gibson, T. W. D. Edwards"Regional water balance trends and evaporation-transpiration partitioning from a stable isotope survey of lakes in northern Canada" 2002

10. JOHN F. FICKE"COMPARISON OF EVAPORATION COMPUTATION METHODS, PRETTY LAKE, LAGRANGE COUNTY, NORTHEASTERN INDIANA"1972

11. MoDeqing, Zhao Ying, Chen Shangsong, "Automatic Measurement and Reporting System of Water Quality Based on GSM," 2012 International Conference on Intelligent System Design andEngineeringApplication.

12. SvetomirMijović1, Bojan Palmar2 1Serbian Environmental Protection Agency, Belgrade, RepublicofSerbia2StateHydrometeorologicalServiceofSerbia, Belgrade,RepublicofSerbia

13. AutomatedWater Quality Monitoring, Field Manual (1999), Ministry of Environment Lands, and Parks, Water Management Branch for the Aquatic Inventory Task Force Resources

InventoryCommittee, TheProvinceofBritishColumbia, andCana da.

14. Mijović S. and Palmar B. (2009). "Continuous water quality monitoring on river Kolubara" $30^{\text {th }}$ scientificprofessionalmeetingwithinternationalparticipation.

15. International Journal For Research In Emerging Science And Technology, Volume-2, Issue-3,March-2015e-Issn:2349-7610

16. Volume-2, Issue-3, March-2015 Copyright ( 2015 Ijrest, All Right Reserved 21

17. MuhammedaliMazdi\& Janice Gillispie "8051 Microcontroller \& embedded system" 3rd editionpearson.

18. Prof.Sachin S. patil ,Prof.S.J.Patil, Prof.M.M.Raste "AIR POLUTANT MONITRING USING SENSOR NETWORKS"International Journal of Advanced Research in Electronics CommunicationEngineering,Volume.3.Issue.8.,.Aug2014,pp..829..-...833.

19. Mr. S.S. Patil,. A.N.Shinde,.A.C.Joshi "WIRELESS TEMPERATURE MONITORING SYSTEM USING WIRELESS SENSOR NETWORKS" in international journal of advancedelectronics and communication engineering,volume-1, issue-4, oct-2012,ISSN-2278-909X,pp46-51,ww,ijarece.com

20. MicrocontrollerchipTechnology,2001,PIC16F84ADatasheetw ww.microchip.com

21. http://www.ti.com/product/LM35

22. Mr. Raguram. R, "Study Of Defects Tolerenced Drilling Of Composite Material", International JournalofComputerTrendsandTechnology(IJCTT)volume3Iss ue 5 Number2Oct 2012 